\title{
Making Connections and Building Confidence: A Study of Specialist Dating Agencies for People with Intellectual Disabilities
}

\author{
Michelle McCarthy ${ }^{1}$ (D) $\cdot$ Karen Milne Skillman ${ }^{1} \cdot$ Nicola Elson $^{1} \cdot$ Claire Bates $^{1}$. \\ Rachel Forrester-Jones ${ }^{2} \cdot$ Siobhan Hunt $^{1}$
}

Published online: 13 February 2020

(c) The Author(s) 2020

\begin{abstract}
Dating agencies are a small, but growing sector of social care provision for people with intellectual disabilities. The research reported here is the first to explore, with 10 specialist agencies in the UK, why they were set up, how they operate, the barriers and problems they encounter and their success or otherwise in facilitating relationships for people with intellectual disabilities. A strong case is made for the proliferation of such services.
\end{abstract}

Keywords Dating · Intellectual disabilities · United Kingdom

\section{Introduction}

Historically, it was difficult for adults with intellectual disabilities to form relationships of their own choosing $[1,2]$. Negative attitudes towards their suitability for, and capabilities regarding, relationships and sexuality led to eugenic practices such as institutionalization (including segregated living), forced abortion and compulsory sterilization in many countries around the world $[3,4]$. Adults with intellectual disabilities were simply not considered to have the same emotional, psychological or social needs for self-fulfilment as other people [5] leading to a denial of their human right to express their sexuality in any form [6].

Although there have been improvements in recent years, many people with intellectual disabilities remain sexually disenfranchised [7]. The lack of importance attached to the potential for them to experience personal fulfilment through intimate relationships is, it has been argued, part of a larger problem: that of simply not recognizing the importance of pleasure in people's lives more generally, be it from food, music, clothes or any other

Disclaimer: The views expressed in this paper are those of the authors and not necessarily those of the NIHR School for Social Care Research or the Department of Health, NIHR or NHS.

Michelle McCarthy

M.McCarthy@kent.ac.uk

1 Tizard Centre, University of Kent, Canterbury, UK

2 Department of Social and Policy Sciences, University of Bath, Bath, UK 
measure of quality of life [8]. Salt et al. [9] state that intellectual disability "remains a risk factor for failing to achieve both the social and psychological transitions associated with adulthood" and this is significant because there is a strong connection between the quality of social and personal relationships and good physical and mental health [10].

Romantic relationships are not the only kind which are difficult to achieve. Platonic ones too can be elusive: evidence suggests that, compared to the general population, more people with intellectual disabilities report having no or very few friends [e.g. 11, 12] and also higher rates of peer bullying, peer abuse and social exclusion [13].

Currently, the rights of people with intellectual disabilities to develop relationships are supported by law, by policies and by guidance. Yet in a recent National Development Team for Inclusion (NDTi) review of relationships for people with intellectual disabilities, Harflett and Turner [14] outlined the wide range of attitudinal and practical barriers people still faced. They also stated (p.14):

Most of the research has focused on identifying barriers and making recommendations rather than looking at what works to support people with learning disabilities to develop relationships.

The main aim of our research was to explore whether and how specialist dating agencies worked to support people with intellectual disabilities to form and maintain relationships.

\section{Literature Review}

\section{Mainstream Dating Agencies and Online Dating}

Modern dating agencies fulfill broadly the same function as traditional matchmakers i.e. third parties who have been bringing people together since antiquity [15]. In many different societies, religions and cultures, such formal matchmaking still occurs though much of the activity has now moved online [16].

Although actual agencies (i.e. with premises and staff who will meet personally with members) do still exist "a 'digital revolution' is underway in regards to dating, courtship and modern romance" [17, p. 271]. This means that today single people tend to look online for prospective partners. Millions of people use such services and through them they have a multitude of potential matches to choose from and can meet people far beyond their own social circles and localities. Whilst choice is generally considered a good thing, the apparently infinite possibilities offered by online dating sites, such as Tinder $^{\mathrm{TM}}$, can pose problems for its users, with some reporting being overwhelmed and with issues relating to addiction [18].

A key difference between online dating and more traditional forms of matchmaking, is that online dating relies predominantly on photographs and therefore physical attraction. Evidence suggests that although dating profiles do have some limited verbal descriptions, people base their romantic decisions primarily on the accompanying photographs [19]. Whilst both men and women look for a partner they find physically attractive, empirical evidence going back decades [e.g. 20,21] indicates that men report they value physical attractiveness in a potential long term partner more than women do [22].

Feminist and disability scholars have long argued that in a society which reflects ableist views, people with disabilities, especially women, are significantly disadvantaged when it comes to being seen as potential romantic partners [23-25]. This poses an obvious problem 
for people with disabilities in presenting themselves on mainstream online dating sites. Not all people with intellectual disabilities have access to computers, mobile phones and social media [26] with which to engage in on-line dating experiences. But where they do, it is easy to see that not being considered conventionally attractive [27], can lead to disappointment as potential partners swipe past their photographs on online dating sites. In relation to women in particular, Araújo, Meira and Almeida [28, p. 419] conclude from their research across many countries that "Some appearance stereotypes... in the physical world follow [women] in the online world". Negative experiences, such as continually being passed over in favour of others, is known to be damaging to a person's sexual self-esteem, especially if they are already vulnerable [29] and can cause people to experience shame [30].

\section{Specialist Dating Agencies for People with Intellectual Disabilities}

It is not difficult to understand why many people with intellectual disabilities may seek formal help with finding a relationship, given the disadvantaged position they start from (see above). Dating agencies are one obvious solution to the problem. Yet there are relatively few of them ${ }^{1}$ and there is very little literature on dating agencies for people with intellectual disabilities. Three papers were found after extensive literature searches [31-33].

Both the Jenner and Gale papers [31,32] report on the same dating agency: the Relationship Support Service (RSS), a pilot project set up by CONSENT, a sexuality support service run by the National Health Service (NHS) for people with intellectual disabilities in Hertfordshire, UK. The idea for the service came from service users asking for opportunities to meet new friends and potential partners. Jenner and Gale conducted a survey of the experiences and views of 150 service users, family carers and support staff/professionals: $70 \%$ of service users said they had few opportunities to meet partners, with $75 \%$ of parents and $96 \%$ of staff agreeing with that statement. When asked if they would use a friendship/dating agency, the response was overwhelmingly positive, with $82 \%$ of service users saying they would use one to find new friends and $78 \%$ to find a partner. Although parents of adults with intellectual disabilities are often assumed to be conservative in their attitudes to relationships, $98 \%$ of parents surveyed they would support their son and daughter to use the service to find friends and $70 \%$ to find a partner.

From the outset, Jenner and Gale report that the service was always more than an introduction agency. It provided education and ongoing support around sex and relationships, as well as workshops for parents and staff training. It was set up as a pilot project to run for a year. It did not continue in the longer term due to lack of funding, rather than any lack of members or lack of success in helping people form friendships and relationships. Indeed, lack of funds was reported as the biggest obstacle to the successful running of the project. Another major barrier, reported in both papers, was the gender imbalance of members: in the early months, $73 \%$ of members were male, $27 \%$ female [31] and towards the end of pilot project, this had barely changed to $71 \%$ male and $29 \%$ female [32].

Jones [33] reports on the establishment of the Mates ' $n$ ' Dates agency in Oxfordshire, UK. It was run along very similar lines to RSS, in that it offered ongoing support and educational workshops, as well as matching individuals. It differed in two ways from RSS, in

\footnotetext{
1 There is no known register of dating agencies for people with intellectual disabilities in the UK, so exact numbers are unknown. However, after extensive online searching and utilising existing networks and contacts in the field, we are confident in saying there were a total of 11 in the UK at the time of this research.
} 
that it also put on regular social events to bring people together and had a separate group called Mingle for people with intellectual disabilities who identified themselves as lesbian, gay, bisexual or transgender (LGBT). Although exact numbers were not given, Jones also reports a gender imbalance in members, with far more men than women. Mates ' $n$ ' Dates was (and still is, over 12 years later) run by the charitable organization Guideposts Trust.

There is precious little written by people with intellectual disabilities themselves about their use of dating agencies, but Jones [34], one of the co-founders of the biggest specialist dating agency, Stars in the Sky, London, wrote about her motivation for setting up the agency, its successes and challenges. She writes from her own perspective of being a person with intellectual disabilities looking for love and struggling to find it. Fairman [35] also wrote very enthusiastically about the specialist dating agency model, describing and praising the work of Stars in the Sky, London, and hoping they would set up a branch in her own area, so she could join. In this paper, we include data concerning the views of people with intellectual disabilities using specialist dating agencies (see below).

\section{Method}

The data from dating agencies was collected for Study 1 of a programme of studies investigating support for adults with intellectual disabilities to form and maintain loving relationships. Other studies in the programme gathered data from 40 adults with intellectual disabilities and 40 family carers and support staff. Findings from the other studies are reported elsewhere [36, 37]. The whole research programme ran from October 2017-April 2019.

\section{Data Collection}

We conducted semi-structured in depth interviews, and collected a small amount of quantitative data, from workers in 10 specialist dating agencies in the UK. ${ }^{2}$ All participants were female and all but one were white. As well as their dating agency work, they had all had experience of intellectual disability services and/or an adult family member with an intellectual disability.

The interview schedule was devised specially for this research project (and is available on request). Questions were asked about the setting up of the service, funding sources, details of how it operated, who it provided a service to, safety and safeguarding concerns, biggest challenges, etc.

Ethical approval was given by the Social Care REC (Ref No 17/IEC08/0053). Study participants were recruited from those who expressed an interest in the project following awareness raising via statutory and voluntary organizations and social networks including the Supported Loving Campaign. In the wider study, which also involved people with disabilities, all of the study participants had capacity to consent, which was sought using information sheets and consent forms, with easy read versions (including the use of pictures) for people with intellectual disabilities. Confidentiality, anonymity and voluntariness were stressed to all participants before, and during the study. Mindful that some participants with intellectual disabilities might find it upsetting to talk about the difficulties they

\footnotetext{
2 One agency was no longer operating, but the co-founder and former worker nevertheless agreed to participate in the research. Nine of the dating agencies were in England and one was in Scotland.
} 
experienced in finding romantic relationships, we arranged for support to be in place for them if they felt they needed it, though in the event, none did.

\section{Data Analysis}

A thematic analysis was conducted on the qualitative data and some descriptive statistics were produced from the quantitative data. Each transcript was read repeatedly to ensure familiarity with the data, then a line by line analysis and initial coding began. Codes were grouped into initial themes, which were in turn re-ordered into over-arching and sub themes (Braun and Clarke 2006). All transcripts were read and coded by two members of the research team independently, with a high level of agreement regarding codes and themes.

\section{Findings}

\section{Dating Agencies}

There was a high degree of similarity in the type of dating agency and the people they served (see Table 1). They did however, vary significantly in size, with membership numbers ranging from 40 to 600 . The agency which had up to 600 at its peak, served the whole of London (and has since closed down). There was no overlap in members between the different agencies, as they were geographically widely spread across the UK.

The main funding streams for the agencies were the National Lottery Community Fund, ${ }^{3}$ charitable foundations, fundraising and membership fees, and a small amount of local authority funding.

Although differing in size, their aims and objectives were all the same i.e. to reduce social isolation by providing safe opportunities for people with intellectual disabilities to meet others for friendship and romance. All the agencies considered it important to offer a personal service to their members: meeting with prospective members in person and spending time getting to know them and what they were looking for. Thus, none had adopted the model of online dating services.

As one would expect, safety was high priority. No agency accepted members without a disability, meaning that any person with an intellectual disability who was seeking a non-disabled partner would have to go elsewhere. All agencies required references from professionals who knew the person well before they would accept members. This was to ensure that the people were (a) who they said they were (i.e. that they did have intellectual disabilities) and; (b) that they did not pose any undue risk to others (e.g. through behaviors that were challenging and/or or criminal). Minor offences, especially those committed some time ago, were not necessarily a bar to membership and would be considered on a case by case basis. However, all agencies said people who had committed sexual or violent offences would not be accepted. A number of agencies pointed out that seeking references from professionals could be quite problematic, with lengthy delays holding up the progression of memberships, or professionals reluctant to provide references, as they were not sure what they should or should not disclose.

\footnotetext{
${ }^{3}$ Formerly known as the Big Lottery Fund.
} 


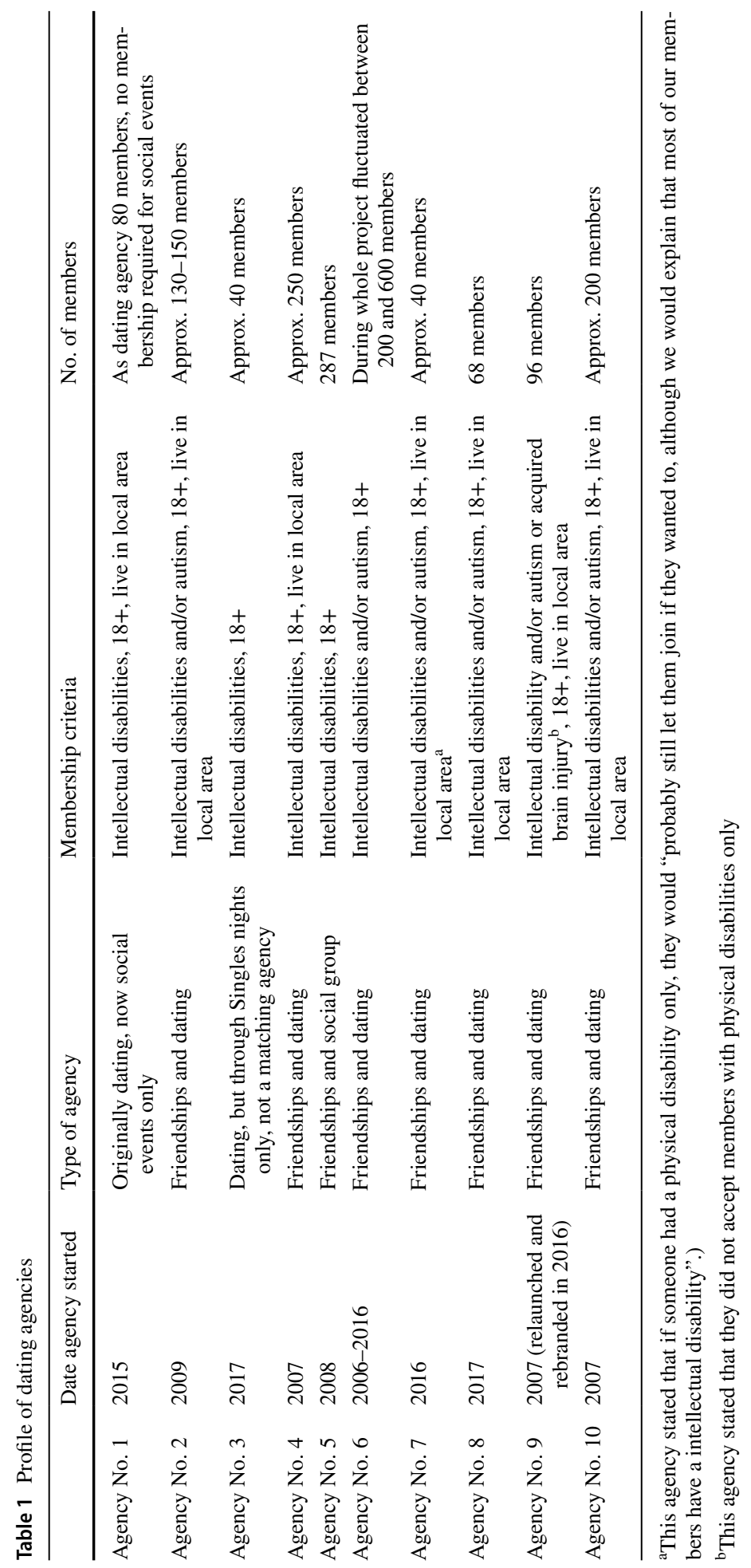


In addition to seeking to screen out any inappropriate members, the agencies who matched people for dates (only No. 3 did not), all provided chaperones for the first, or first few, dates. Where members needed chaperoning in the longer term, one or two agencies were able to provide this, but others were not and tried to facilitate such arrangements from the members' own networks of support, including their families. Some agencies did not see this as problematic, although others did: "We don't think anyone should have to have a date with their parents there". (6)

Most agencies encouraged some level of involvement of family carers or support staff in their members' dating activities, as they recognized that often people needed emotional and practical help with arrangements, including travel. When people with intellectual disabilities still lived with their parents, or were in residential or supported accommodation, then agencies took the view that, as long as the member was in agreement, it was unrealistic and probably counter-productive to try to exclude parents and staff. However, a minority of agencies discouraged, particularly, parental involvement "because their beliefs or attitudes can heavily influence the situation and not always in a good way" (2).

\section{Thematic Analysis}

The thematic analysis resulted in four main themes, each consisting of two sub-themes (Fig. 1).

\section{Gender Imbalance}

One of the biggest challenges to the smooth running of dating agencies was that they all had far more men than women joining them. This pattern applied across all 10 agencies, although one maintained a 50/50 gender split in membership by holding men on waiting list until sufficient numbers of women joined. The extent of the gender imbalance varied from the extreme $95 \%$ male/5\% female to the somewhat more balanced $60 \%$ male/40\% female. The most common level of imbalance was $66 \%$ male $/ 33 \%$ female.

In terms of the two sub- themes which fed into this main theme of gender imbalance, one was general and one specifically related to people with intellectual disabilities.
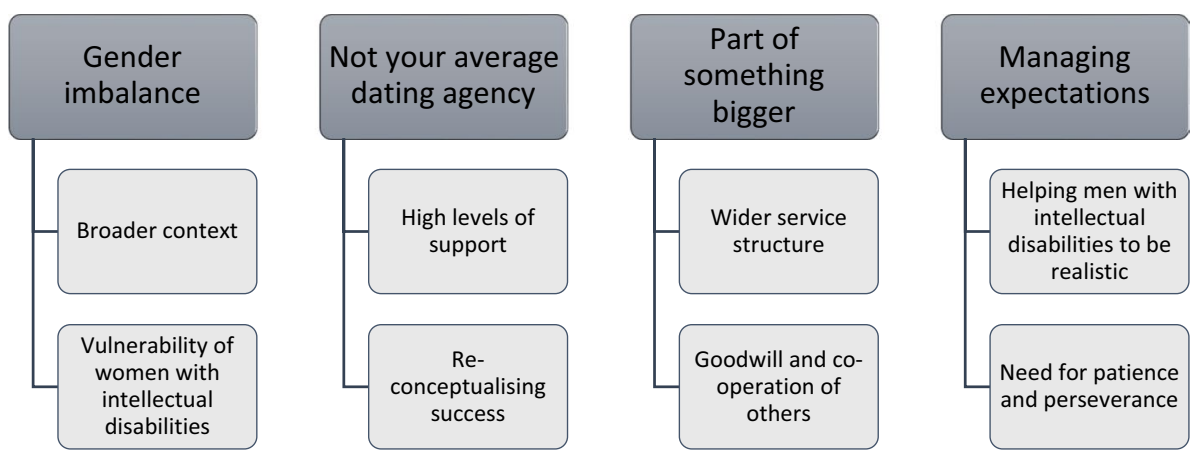

Fig. 1 Main themes 


\section{General Gendered Context for Dating}

The general theme raised by dating agency staff was their knowledge of the overall context for gender imbalance in dating agencies and sites. They believed, and evidence suggests they are right, that men outnumber women on many of the biggest dating sites, e.g. Tin$\operatorname{der}^{\mathrm{TM}}$ [38]. This pattern was also found in the traditional newspaper 'lonely hearts' advertisements which preceded online dating [39]. Researchers such as Jagger suggest this is because historically and culturally men have taken the initiative in romantic and sexual encounters and thus it is also the case when it comes to 'advertising' oneself for love. Not surprisingly, similar patterns are found amongst people with intellectual disabilities, since having an intellectual impairment does not eradicate gendered behavior. Indeed, it has long been argued that the opposite is the case, with both men and women with intellectual disabilities adopting sometimes quite rigid gendered stereotypes [40, 41]. Interviewees frequently mentioned differences in male and female sexuality as a reason for the higher numbers of male members in dating agencies. For example:

Sexual desire is more overt in men, they are more forthcoming about wanting a sexual relationship (3)

Male sexuality is more of an obvious need. Very few women came looking for relationships, most were looking for friendships. (6)

\section{Vulnerability of Women with Intellectual Disabilities}

The second sub-theme, which related specifically to people with intellectual disabilities, concerned the vulnerability of women with intellectual disabilities to sexual exploitation and abuse. Research evidence confirms the widespread belief in society that women generally, and those with intellectual disabilities specifically, are at heightened risk of sexual abuse compared to male peers [42]. Consequently, both support staff and family carers feel girls and women with intellectual disabilities need more protection, and a lower level of sexual freedom, than boys and men [43, 44]. Service providers also feel pressured to prioritize safeguarding over all other outcomes, despite the fact that some level of experimentation and positive risk-taking is required for healthy development and transition to adulthood [45]. Fears about women with intellectual disabilities potentially being abused during the dating process were reported to us by many of the dating agency staff when they were asked to explain the lower number of female members:

I think the main reason there were less girls was because the families were overprotective of them (1)

Reasons for gender imbalance? ... A lot of the women have had previous abusive relationships. (3)

The men are more like gung-ho, they know what they want, they are happy to get out there and the parents have been more supportive. With women ...yeah, parents are definitely more protective of the women. (8)

Faced with the gender imbalance in members, most agencies had tried to overcome this by offering membership fee discounts or even free membership to women, putting on events to specifically attract women ('Ladies nights"), approaching local groups for women with intellectual disabilities. These had very limited or no effect, membership remained imbalanced and this led to male members getting frustrated at the length of time it took to find them a date. 


\section{“Not Your Average Dating Agency"}

\section{High Levels of Support}

The second main theme related to the differences between specialist agencies for people with intellectual disabilities and mainstream ones. These agencies all gave far more support to people than a mainstream dating service would, both at the matching stage and ongoing support throughout relationships. People were offered personal support before dates, to help them prepare, during initial dates (through chaperones to provide support and build confidence) and after dates in both the short and long term. In fact, many of the agencies reported that individuals and couples who had met through their agency may return months, sometimes years later, for ongoing relationship support.

The agencies also provided educational workshops on many topics relating to sexuality and relationships as well as a very wide range of social opportunities for their members including: discos; Karaoke nights and formal balls (e.g. at Christmas or Valentine' Day); music festivals and camping trips; bowling; theatre trips; performing arts events and everything in between.

This level of support led to people with intellectual disabilities experiencing a great sense of loyalty to the dating agencies. The men and women with intellectual disabilities in our wider study reported seeing the dating agencies as organizations they really identified with and belonged to:

Before I joined [agency no. 9] I was more like...shut off from the world really.

Now, I feel like I belong here.

Joining [agency no. 7) is the best thing I've ever done.

The feeling of being accepted, respected and valued within an organization has been found elsewhere (in relation to self-advocacy groups) to be highly significant in terms of a creating a sense of belonging [46].

\section{Re-Conceptualising Success}

Mainstream dating services commonly promote themselves by stating the number of successful long-term relationships and marriages they have helped to create. However, in terms of these traditional markers of success for dating agencies, as Table 2 shows, numbers for these were quite modest for the specialist dating agencies:

Whilst these figures may appear relatively disappointing, one striking aspect of our findings was that the agencies had a much broader, and more fluid, definition of success than just marriages or long term relationships. They included in their 'success rate' people who may never have had a date, but who may have made a friend. They included people who developed a social life after joining, when they had previously been socially isolated. Some social events run by dating agencies attempted to differentiate themselves from other social events by deliberately incorporating elements to bring people closer together e.g. at Karaoke nights songs had to be sang in a duet. They included those people whose confidence had grown since becoming members. This broad definition of success is entirely justified in the context of the primary aim of all the agencies being to reduce social isolation and provide opportunities for friendship and romance. 
Table 2 Long term relationships

How many long term relationships they have helped to create

\begin{tabular}{ll}
\hline Agency No. 1 (2015-2016) & 1 \\
Agency No. 2 (2009-) & 7 (3 marriages, 3 engagements, 1 long term relationship) \\
Agency No. 3 (2017-) & 0 \\
Agency No. 4 (2007-) & 10 \\
Agency No. 5 (2008-) & 1 (engagement) \\
Agency No. 6 (2006-2016) & 30 (including 4 marriages and 1 gay blessing service) \\
Agency No. 7 (2016-) & 4 \\
Agency No. 8 (2017-) & 5 \\
Agency No. 9 (2007-) & 10 (including 2 marriages) \\
Agency No. 10 (2007-) & 5 (including 4 marriages) \\
\hline
\end{tabular}

\section{Part of Something Bigger}

\section{Wider Service Structure}

The third main theme relates to the organizational structure of the agencies. It appeared to be an important factor that agencies were part of a bigger organization. Only two of the agencies (Nos. 1 and 8) were independent entities and both were set up by family members concerned about the lack of safe dating opportunities for their relative. One of them ceased the dating side of its work after a year and subsequently concentrated solely on social events. The other had set out to cover the whole of London and subsequently had to scale back to focus on one part of the city. This agency had a complicated fee structure and was one of the two most expensive agencies in the study. It seemed to be inherently more difficult for these standalone dating agencies to operate; neither were seeking to be profit making, but even covering their costs was problematic, as they could not charge high fees due to the vast majority of their client base being people with intellectual disabilities on low incomes.

\section{Goodwill/Co-operation of Others}

The remaining eight agencies were all affiliated to, or run by charity or $3^{\text {rd }}$ sector organizations. This proved to be very important, as these wider organizations not only funded the agencies to some extent, but also provided a lot of support 'in kind' particularly office space, help with fundraising and some running costs. This was important because it freed up the agency staff to concentrate on their core mission i.e. to support people with intellectual disabilities to find dates and develop relationships. All ten agencies emphasised that they relied a lot on the goodwill, co-operation and support of either their umbrella organization and/or other supportive services.

\section{Managing Expectations}

The final main theme related to managing expectations and there were two sub-components of this. 


\section{Helping Men with Intellectual Disabilities to be More Realistic}

Elsewhere in the specialist dating agency literature it has been noted that some men with intellectual disabilities were "exacting in their requirements", indeed unrealistic, when it came to women they wanted to meet [33, p. 12] and we found the same in this research. Agencies reported that often, men would have unrealistic ideals of what their date should look like:

The men all wanted a Bay Watch girl. (1)

They have a picture in their head about the perfect person they want to meet. (7)

Agency workers reported having to spend time working sensitively with such members to help them understand that by being so specific about what they were looking for, they were inevitably limiting their options and setting themselves up for disappointment. The men had to be helped to understand that the agency simply could not provide what they were looking for: "We don't have a magic box of girls they can choose from." (10)

\section{Need for Patience and Perseverance}

The second way in which agencies had to help people manage their expectations was by helping people understand that it can take a long time to find the right person and not to expect instant success. Agencies found that when people with intellectual disabilities were unused to dating, they may expect to fall in love with the first person they meet and were disappointed when this did not happen or when their feelings were not reciprocated. Agencies had to sometimes work hard with individuals to help them understand that finding the right person can take some time and not to give up too easily: "When people don't have any experience, they just don't know how relationships work-it's understandable...that knowledge can only really come from experience" (8)

\section{The Views of People with Intellectual Disabilities About Dating Agencies}

As stated above, in another study in the wider research programme, we interviewed 40 adults with intellectual disabilities about their experiences, expectations and hopes around love and romance with part of the interview focusing on how they viewed dating agencies. We report on the relevant findings regarding dating agencies here.

Only one-third of our sample had any experience of dating agencies, therefore the data is small, but nevertheless important.

The views of people with intellectual disabilities on mainstream dating were universally negative, with actual agencies being described as being far too expensive and not really helping individuals: "All they are interested in is getting your money." Some people had tried mainstream speed dating and found that it had not worked for them: "You have to be really, really quick, it was like a job interview...it didn't work, because it takes me about half an hour to get my words out."

None of those who had tried online dating had positive experiences:

They used to pick on me. They saw my picture and they was playing a game with me...internet dating is not a good place, you get people looking for sex, you get people looking to take the mickey out of you...it was extremely bad, I think it's full of 
weirdos out there.

I have been on Tinder, but I didn't have a very good experience. This guy said he

liked me and all that, then he started to send me pictures of his you-know-what.

There was particular concern that online, you never really knew who were talking to, whether they were trustworthy and therefore the general consensus was that it was very risky:

You never know if they're going to be a paedophile or a murderer

It could be somebody pretending to be somebody else.

The low self-esteem of some people with intellectual disabilities was also evident, as some participants expressed beliefs that a 'normal' person would not be attracted to them. Therefore they thought there was something suspicious about anyone who said they were:

I'm thinking... why would those girls want to meet me? I mean, they can find a better date than me.

Why would...there's always a little bit of a question mark over someone who is interested in someone with that has a learning disability.

However, when it came to their experience of using specialist dating agencies for people with intellectual disabilities, the picture was quite different. Most of our sample were very positive, both about the social events they went to, but also the one-to-one dates. In particular, people spoke about appreciating the chaperones they had for their first few dates ("I just felt like I was safe, knowing she was there if anything went wrong") and about the ongoing advice and support they received regarding relationships.

It was also clear that some people appreciated knowing they would be matched for a date with another person with a disability and this gave them reassurance that they would find acceptance rather than rejection:

If they're like me, then I'm happy to give it a go

I want to find someone who will accept my disability and if they've got one themselves, then they will.

However, there were some dissenting voices and these were people who were frustrated by having to wait a long time to be matched for a date and those who felt they had been matched with people less able than themselves.

\section{Discussion}

There is very little extant literature with which to compare our findings, but that which does exist [31-33], reports findings very much in line with those reported here. This is despite a period of some 10-13 years having passed since the previous research studies were published. Areas of commonality in findings relate to the gender imbalance and the wide ranging nature of relationship support offered to people with intellectual disabilities.

Although gender issues emerged as a very strong finding in this research, there are other equality and diversity issues to consider. All the agencies were, in principle, inclusive to all people with intellectual disabilities, though in practice most had very few LGBT members. This meant that it was very difficult to match LGBT people for dates, which was obviously frustrating for them. Some agencies sought to support their LGBT applicants or members by referring them elsewhere, though all acknowledged that mainstream LGBT groups were 
unlikely to offer the levels of support people with intellectual disabilities needed. Some agencies had set up separate social and support groups for people with intellectual disabilities who identified as LGBT, which they reported were successful and popular with members. However, these LGBT groups were reported to be most frequently used by male members, with women very much in the minority [see also 46].

Similar to the above, whilst in principle the dating agencies were open to people of all ethnic and cultural backgrounds, only the two based in London had an ethnically diverse membership. The other eight agencies had an overwhelmingly white British membership, despite efforts to recruit members from more diverse communities. In one area (Yorkshire, UK) an alternative social group for adults with intellectual disabilities from South Asian communities has been formed. Hum Tum describes itself as a culturally-sensitive alternative to existing friendship projects for people with intellectual disabilities, one which recognizes the cultural and religious preferences of its members by holding male-only and female-only events at venues that do not serve alcohol.

Whilst all the agencies were open to all people with intellectual disabilities over the age of 18 , the age profiles of their members tended to be younger, with the majority of agencies reporting that most members were in early to middle adulthood (18-44 years). Only a minority of agencies reported having a good number of members in the 45-60 age range and only a very few members over the age of 60 were reported. This is perhaps not surprising, but does suggest the relationship needs of the over $45 \mathrm{~s}$ may be being neglected and agencies may need to be pro-active in making sure they attract and meet the needs of the older age group.

Though not usually thought of as an equality or diversity issue, we certainly found there were particular issues for people with intellectual disabilities who lived in rural areas. All the agencies outside of London covered large geographical areas, sometimes whole counties. The disadvantages faced by people with intellectual disabilities living in rural areas were clear and related largely to poor or non-existent public transport, which made it very difficult for them to broaden their social and relationship horizons.

\section{Limitations}

This research had limitations, as all studies do. Firstly, it is not an independent evaluation of the dating agency services, but rather relies on self-reports from those people who ran (and used) them, thus there may be unknown biases. Secondly, it is limited to one country, the UK, and different results may have been found from dating agencies in other countries. Nevertheless, it does give the first overview of why and how such services operate and so will hopefully encourage others to explore the model.

\section{Conclusion}

With the rise of online dating, the stigma which was once attached to using a 'lonely hearts' advert, a dating site or agency has largely disappeared [47]. Whilst informal support from family, friends and support staff is obviously important, dating agencies, as a model of formal relationship support for adults with intellectual disabilities also have a clear role.

Indeed, we argue in this paper that dating agencies for people with intellectual disabilities are an important counter-balance to some of the negative and infantilising attitudes 
which still exist towards people with intellectual disabilities. They can, and do, help people with intellectual disabilities achieve valued social roles as adults in their own communities through making friends, finding partners and living an 'ordinary' life.

The authors are aware that in promoting a segregated service, they are going against the policy and practice thrust of integrating people with intellectual disabilities into mainstream services, which is not something to be done lightly. However, this recommendation is in response to the lived experience of people with intellectual disabilities in the world as it is, rather than the world as we would like it to be. One of the few other authors to write about dating agencies for people with intellectual disabilities concluded that:

The Dating Agency movement is going right against this philosophy [of inclusion]. According to the logic of normalisation, pressure should be put on mainstream dating agencies, night clubs and other services for sex and romance to accommodate the needs of people with learning disabilities. But this is not going to happen and there is a great challenge for service providers when individuals ask to live aspects of life in a segregated rather than 'socially included' way [46, p. 19].

Jones came to the above conclusion after hearing, as we did, from people with intellectual disabilities that mainstream dating options rarely worked out well for them, often costing them a great deal of money and risking their dignity and safety [33].

Most people with intellectual disabilities are aware that they have intellectual disabilities and they are aware that other people tend to view them negatively [47]. It is not surprising then that many people with intellectual disabilities positively want to use a specialist dating service, where they stand less chance of being ridiculed, insulted, or ignored.

Acknowledgements This paper presents independent research funded by the National Institute of Health Research (NIHR) School for Social Care Research.

Data Availability The research project reported here has produced a video freely available to all. Its aim is to inspire social care practitioners to consider setting up a dating agency themselves. The video features existing dating agency service providers and people with intellectual disabilities who have used their services. It can be viewed here https://vimeo.com/336573029. A more general video made for, and with, people with intellectual disabilities discussing how important relationships are for them is available here https://vimeo .com/332887161.

\section{Compliance with Ethical Standards}

Conflict of interest All Authors declares that they have no conflict of interest.

Ethical Approval Ethical approval was given by the Social Care REC Ref No 17/IEC08/0053.

Open Access This article is licensed under a Creative Commons Attribution 4.0 International License, which permits use, sharing, adaptation, distribution and reproduction in any medium or format, as long as you give appropriate credit to the original author(s) and the source, provide a link to the Creative Commons licence, and indicate if changes were made. The images or other third party material in this article are included in the article's Creative Commons licence, unless indicated otherwise in a credit line to the material. If material is not included in the article's Creative Commons licence and your intended use is not permitted by statutory regulation or exceeds the permitted use, you will need to obtain permission directly from the copyright holder. To view a copy of this licence, visit http://creativecommons.org/licenses/by/4.0/. 


\section{References}

1. Lesseliers, J.: A right to sexuality? Br. J. Learn. Disabil. 27, 137-140 (1999)

2. Carson, I., Docherty, D.: Friendships, relationships and issues in sexuality, In: Race, D. (ed.) Learning disability—a social approach, pp. 139-153. Routledge, London (2002)

3. Kempton, W., Kahn, E.: Sexuality and people with intellectual disabilities: a historical perspective. Sex. Disabil. 9(2), 93-111 (1991)

4. Jahoda, A., Wilson, A., Stalker, K., Cairney, A.: Living with stigma and the self-perceptions of people with mild intellectual disabilities. J. Soc. Issues 66(3), 521-534 (2010)

5. Swango-Wilson, A.: Caregiver perceptions and implications for sex education for individuals with intellectual and developmental disabilities. Sex. Disabil. 26(2), 75-81 (2008)

6. Box, M., Shawe, J.: The experiences of adults with learning disabilities attending a sexuality and relationship group: "I want to get married and have kids". J. Fam. Plan. Reprod. Health Care 40, 82-88 (2014)

7. Taylor Gomez, M.: The S words: sexuality, sensuality, sexual expression and people with intellectual disability. Sex. Disabil. 30(2), 237-245 (2012)

8. Alexander, N., Taylor Gomez, M.: Pleasure, sex, prohibition, intellectual disability, and dangerous ideas. Reprod. Health Matters 25(50), 114-120 (2017)

9. Salt, E., Melville, C., Jahoda, A.: Transitioning to adulthood with a mild intellectual disability-young people's experiences, expectations and aspirations. J. Appl. Res. Intellect. Disabil. 32(4), 901-912 (2019)

10. Ward, K.M., Atkinson, J.P., Smith, C.A., Windsor, R.: A friendships and dating program for adults with intellectual and developmental disabilities: a formative evaluation. Intellect. Dev. Disabil. 51(1), 22-32 (2013)

11. Forrester-Jones, R., Carpenter, J., Coolen-Schrijner, P., Cambridge, P., Tate, A., Beecham, J., Wooff, D.: The social networks of people with intellectual disability living in the community 12 years after resettlement from long-stay hospitals. J. Appl. Res. Intellect. Disabil. 19(4), 285-295 (2006)

12. Sango, P.N., Forrester-Jones, R.: Intellectual and developmental disabilities, spirituality and religion: a systematic review 1990-2015. J. Disabil. Relig. 21(3), 280-295 (2017)

13. Baines, S., Emerson, E., Robertson, J., Hatton, C.: Sexual activity and sexual health among young adults with and without mild/moderate intellectual disability. BMC Public Health 18(1), 667 (2018)

14. Harflett, N., Turner, S.: Supporting people with learning disabilities to develop sexual and romantic relationships. National Development Team for Inclusion (NDTi). Available from https://www.ndti.org. uk/resources/publications/the-right-to-a-relationship. Accessed 31 Jan 2020

15. Noy, D.: Matchmakers and marriage-markets in antiquity. Echos du monde classique: Classical Views 34(3), 375-400 (1990)

16. Agrawal, A.: Cyber-matchmaking among Indians: re-arranging marriage and doing 'kin work'. South Asian Popul. Cult. 13(1), 15-30 (2015)

17. Hobbs, M., Owen, S., Gerber, L.: Liquid love? Dating apps, sex, relationships and the digital transformation of intimacy. J. Sociol. 53(2), 271-284 (2017)

18. Orosz, G., Tóth-Király, I., Bőthe, B., Melher, D.: Too many swipes for today: the development of the Problematic Tinder Use Scale (PTUS). J. Behav. Addict. 5(3), 518-523 (2016)

19. de Vries, J.M.: Impact of self-descriptions and photographs on mediated dating interest. Marriage Fam. Rev. 46, 538-562 (2010)

20. Powers, E.A.: Thirty years of research on ideal mate characteristics: what do we know? Int. J. Comp. Sociol. 21, 109-118 (1971)

21. Feingold, A.: Gender differences in effects of physical attractiveness on romantic attraction: a comparison across five research paradigms. J. Pers. Soc. Psychol. 59, 981-993 (1990)

22. de Vries, J.M., Swenson, L., Walsh, R.P.: Hot picture or great self-description: predicting mediated dating success with parental investment theory. Marriage Fam. Rev. 42(3), 7-34 (2008)

23. Fine, M., Asch, A.: "Disabled Women: sexism without the Pedestal. J. Sociol. Soc. Welf. 8(2), 233248 (1981)

24. Monteleone, R., Forrester-Jones, R.: "I honestly feel like I'm not there or something": a qualitative study of the experience of intellectual disability. J. Intellect. Disabil. Res. 60(7-8), 710 (2016)

25. Bates, C., Terry, L., Popple, K.: Partner selection for people with intellectual disabilities. J. Appl. Res. Intellect. Disabil. 30(4), 602-611 (2017)

26. White, P., Forrester-Jones, R.: Valuing e-inclusion: social media and the social networks of adolescents with intellectual disability. J. Intellect. Disabil. (2019). https://doi.org/10.1177/1744629518821240

27. Gerschick, T.: The body, disability, and sexuality. In: Seidman, S., Fischer, N., Meeks, C. (eds.) Handbook of the New Sexuality Studies. Routledge, London, New York (2006) 
28. Araújo, C.S., Meira, W., Almeida, V.: Identifying stereotypes in the online perception of physical attractiveness. International Conference on Social Informatics, pp. 419-437. Springer, Cham (2016)

29. Mayers, K., Heller, D., Heller, J.: Damaged sexual self-esteem: a kind of disability. Sex. Disabil. 21(4), 269-282 (2003)

30. Clapton, N.E., Williams, J., Jones, R.S.: The role of shame in the development and maintenance of psychological distress in adults with intellectual disabilities: a narrative review and synthesis. J. Appl. Res. Intellect. Disabil. 31(3), 343-359 (2018)

31. Jenner, P., Gale, T.: A relationship support service for people with learning disabilities. Tizard Learn. Disabil. Rev. 11(2), 18-25 (2006)

32. Jenner, P., Gale, T.: The relationship support service: an update. Tizard Learn. Disabil. Rev. 11(4), 38-44 (2006)

33. Jones, C.: Friendship, romance and possibly more. Learn. Disabil. Pract. 12(2), 8-14 (2009)

34. Jones, L.: Reach for the stars. Community Living 19(1), 24-25 (2005)

35. Fairman, L.: Stars in the Sky: make a date. Our Say (2008)

36. McCarthy, M., Bates, C., Milne Skillman, K., Elson, N., Forrester-Jones, R., Hunt, S.: What people with learning disabilities think about the support they get to have the relationships they want (in preparation)

37. Bates, C., McCarthy, M., Milne Skillman, K., Elson, N., Forrester-Jones, R., Hunt, S.: 'She misses the subtleties and I have to help make the invisible visible': the role of family carers in supporting adults with intellectual and developmental disabilities with intimate relationships (in preparation)

38. Iqbal, M.: 18-24 Tinder Revenue and Usage Statistics (2019). http://www.businessofapps.com/data/ tinder-statistics/ Accessed 8 May 2019

39. Jagger, E.: Is thirty the new sixty? Dating, age and gender in a postmodern, consumer society. Sociology 39(1), 89-106 (2005)

40. McCarthy, M.: Sexuality and women with learning disabilities. Jessica Kingsley Publishers, London (1999)

41. Scior, K.: Using discourse analysis to study the experiences of women with learning disabilities. Disabil. Soc. 18(6), 779-795 (2003)

42. Barger, E., Wacker, J., Macy, R., Parish, S.: Sexual assault prevention for women with intellectual disabilities: a critical review of the evidence. Intellect. Dev. Disabil. 47(4), 249-262 (2009)

43. Gilmore, L., Chambers, B.: Intellectual disability and sexuality: attitudes of disability support staff and leisure industry employees. J. Intellect. Dev. Disabil. 35(1), 22-28 (2010)

44. Pownall, J.D., Jahoda, A., Hastings, R., Kerr, L.: Sexual understanding and development of young people with intellectual disabilities: mothers' perspectives of within-family context. Am. J. Intellect. Dev. Disabil. 116(3), 205-219 (2011)

45. Seale, J., Nind, M., Simmons, B.: Transforming positive risk-taking practices: the possibilities of creativity and resilience in learning disability contexts. Scand. J. Disabil. Res. 15(3), 233-248 (2013)

46. Strnadová, I., Johnson, K., Walmsley, J.: “... but if you're afraid of things, how are you meant to belong?" What belonging means to people with intellectual disabilities? J. Appl. Res. Intellect. Disabil. 31(6), 1091-1102 (2018)

47. Logeswaran, S., Hollett, M., Zala, S., Richardson, L., Scior, K.: How do people with intellectual disabilities construct their social identity? A review. J. Appl. Res. Intellect. Disabil. 32(3), 533-542 (2019)

Publisher's Note Springer Nature remains neutral with regard to jurisdictional claims in published maps and institutional affiliations. 